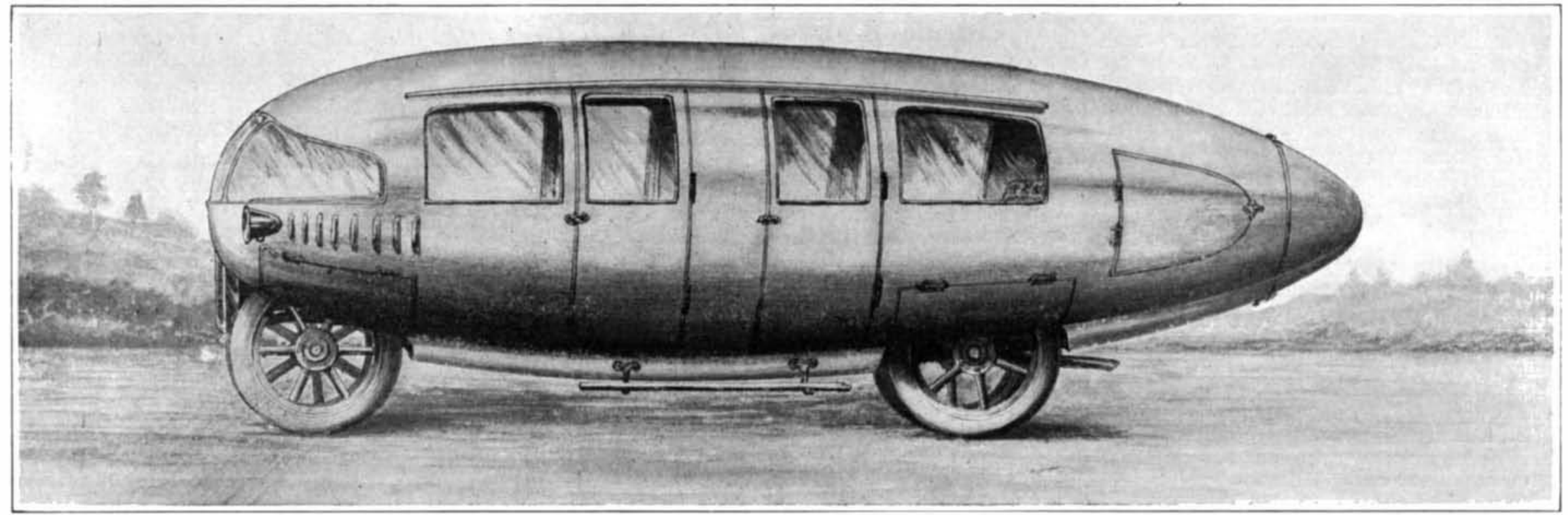

In outward appearance the "car of the future" resembles a submarine boat more than it does a carriage. Its long cigar-shaped body incloses everything except the wheels, and even they are covered for almost half of their diameter.

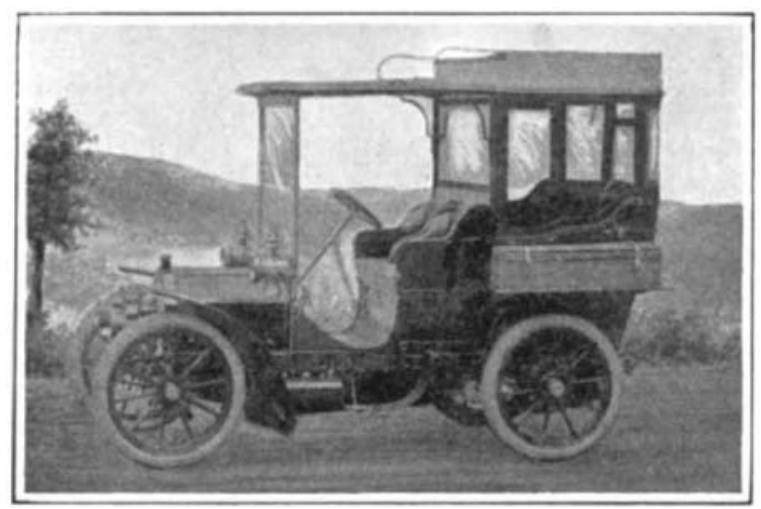

Fig. 1.-Car built for the German Emperor in 1903. It had a rear entrance, proof that the problem of efficient mudguards and running boards had not yet been solved.

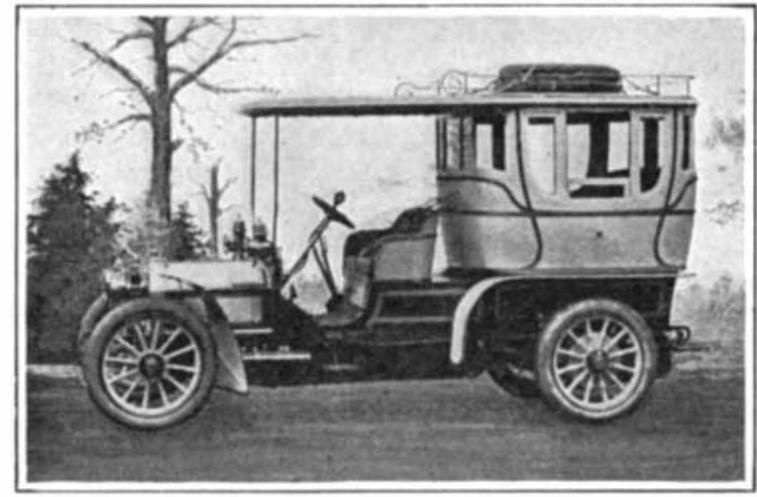

Fig. 2.-A car designed for the German Emperor in 1905. There are still unmistakable signs of the carriage maker's hand.

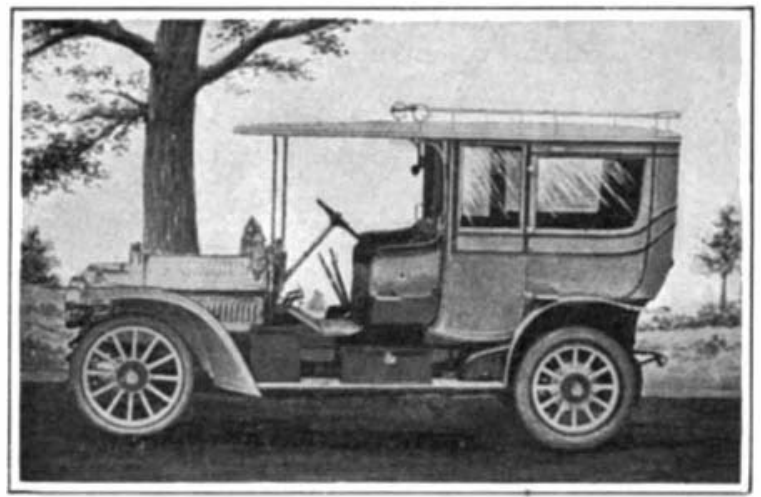

Fig. 3.-The German Emperor's 1907 car. Although it would not attract much attention to-day, the seat backs are stiff and vertical, the upholstery seat backs are stiff and vertical, the uphol
hard and thin. The driver has no protection.

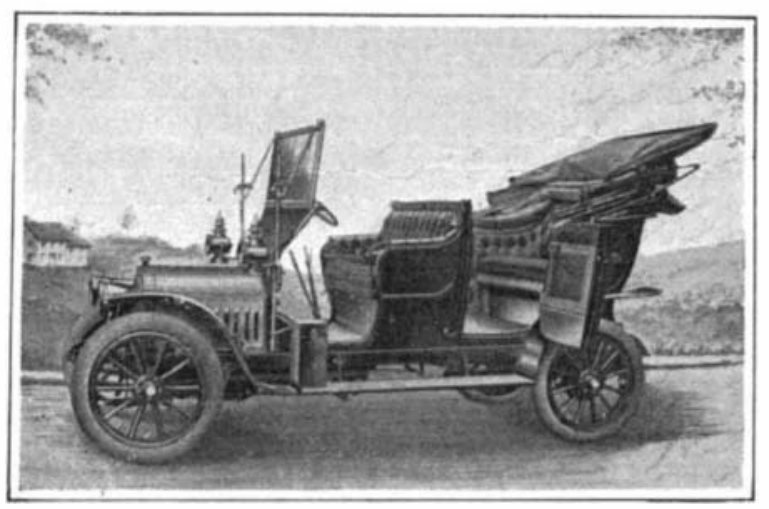

Fig. 4.-A touring car of 1909

\title{
The Future Car
}

How Car Bodies Have Developed at Home and Abroad

By Walter Baunard

\begin{abstract}
In automobile designing as well as in political movements coming events cast their shadows before them. If we would visualize the car of the future, we have only to study the car of the past. That is the object of this article. In order to obtain a correct impression of the automobile of the future, the author has presented and criticised both the European and American cars designed during the last twelve years.-Епiтor.
\end{abstract}

THAT the first automobile bodies were in all respects 1 nothing but adaptations of the older carriage bodies, is fairly well known. Many of the readers of this periodical will remember the first cars of a dozen years ago, and their awkward appearance. They were the product of a compromise-and, like most compromises, were very unsatisfactory. That the motor promises, were very unsatisfactory. That the motordriven carriage was a thing apart and different from
the horse-drawn rig early became evident to thoughtful the horse-drawn rig early became evident to thoughtful designers of automobile bodies. But while they well realized the necessity of striking out in different directions, they were not at all anxious to make radical innovations. The conservatism of the majority of the human race resents upheavals of any kind, preferring rather a gradual elimination of the undesirable. The rather a gradual elimination of the undesirable. The change from carriage body to automobile body therefore had to be made slowly, and at the present time
we have about arrived at the half-way station. The we have about arrived at the half-way station. The automobile of the future will look no more like the motor car of to-day than the limousine of 1913 looks like the $d o s-\dot{\boldsymbol{d}}-d o s$ of 1896 . The limousine or torpedo touring car of the present year is but a link in the gradual transformation of the horse-drawn buggy into the completely enclosed, dust-proof, silent and comfortable "car of the future"

In outward appearance the "car of the future" resembles a submarine boat more than it does a carriage. Its long cigar-shaped body incloses everything except the wheels, and even they are covered for almost half of their diameter. To the eye of the motorist of 1913 it may present too "squat" an appearance, owing chiefiy to the low position of the body. The car has no running boards, no hood, no mudguards, no windshield and no fiapping top. The motor is carried in front of the driver, as in the ordinary motor car, while the various indicators are placed within easier reach of the driver's hand than is possible in the orthodox vertical or sloping dashboard arrangement. The curved plate-glass front of the body affords a clear view of the road ahead, while giving absolute protection from wind, dust and rain. Ventilation is achieved by narrow slits in the sides and top of the car. Conforming to the shape of the body, the doors are curved, reaching so close to the ground that an eleven-inch step is all that is necessary to enter the car. Ample space is provided in the rear of the hollow body for baggage and the carrying of spare tires and other parts, while the seating arrangements allow each passenger more room than he would have in a modern limousine, and fur more than in the various seven-passenger models of the present day. Wind resistance and the duuger

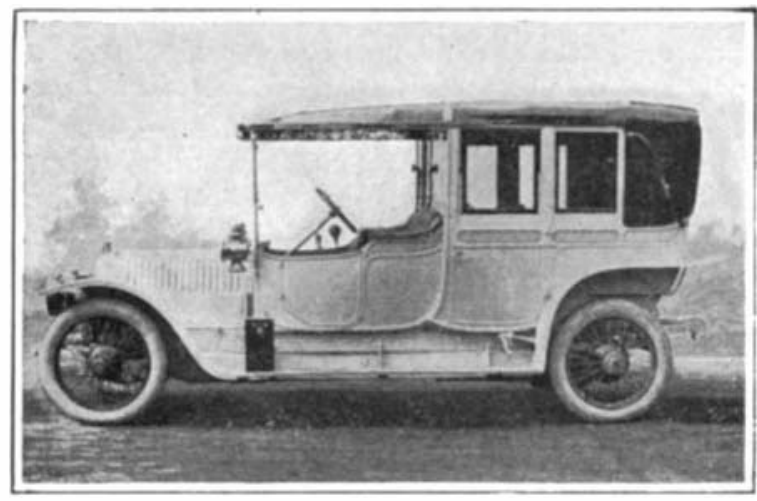

Fig. 5.-A splendid car built in 1910 for the President of France. Fore doors appear for the first time.

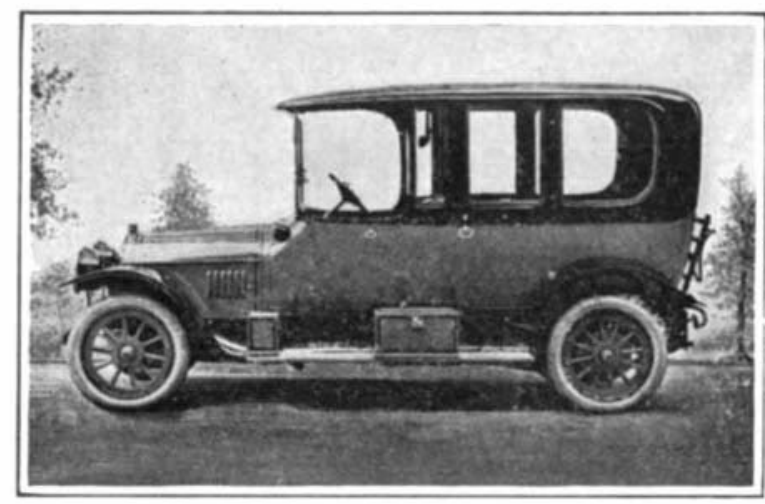

Fig. 6.-A 1912 model, which, were it not for the presence of the tool box in the very middle of the running board, might be considered more beautiful than the graceful car shown in Fig. 7.

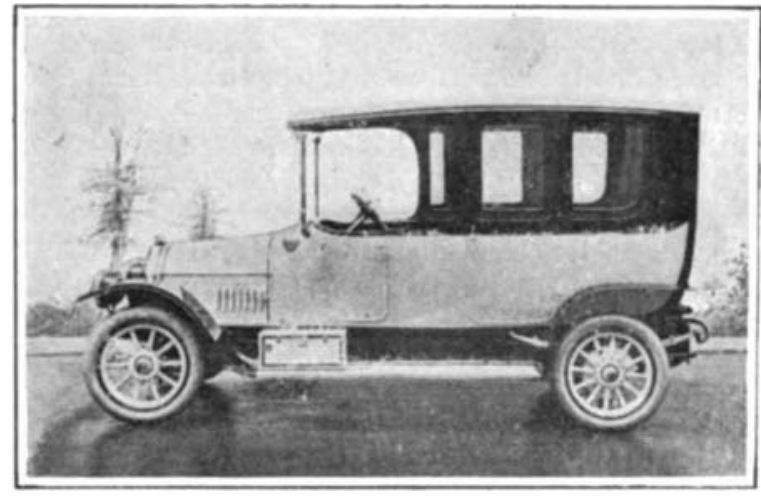

Fig. 7.-A 1913 German model, a good example of neat designing.

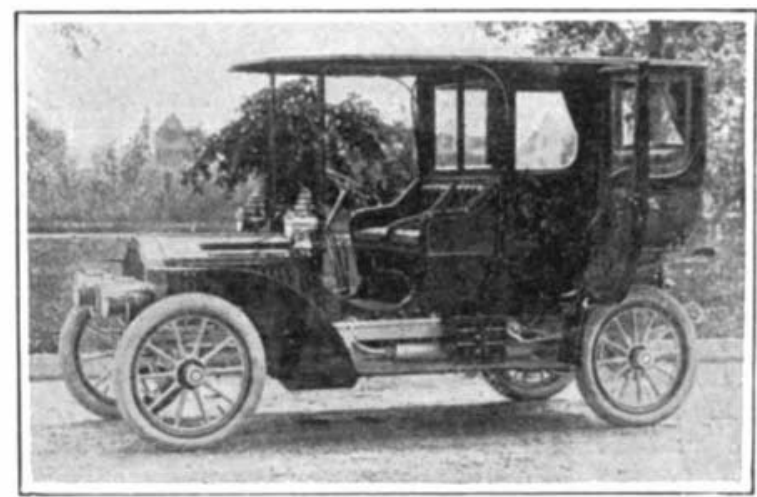

Fig. 8.-A 1905 American limousine. 


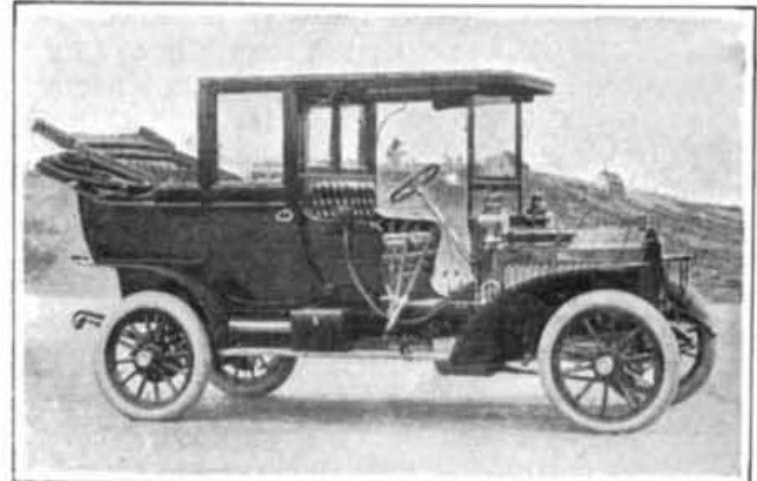

Fig. 9._A 1907 American landaulet.

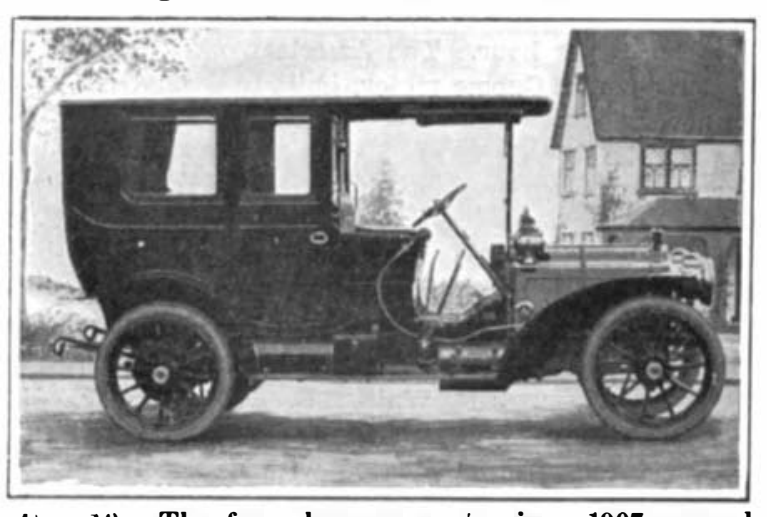

Fig. 10.-The few changes made since 1907 caused many to think this 1909 model the "car of perfection."

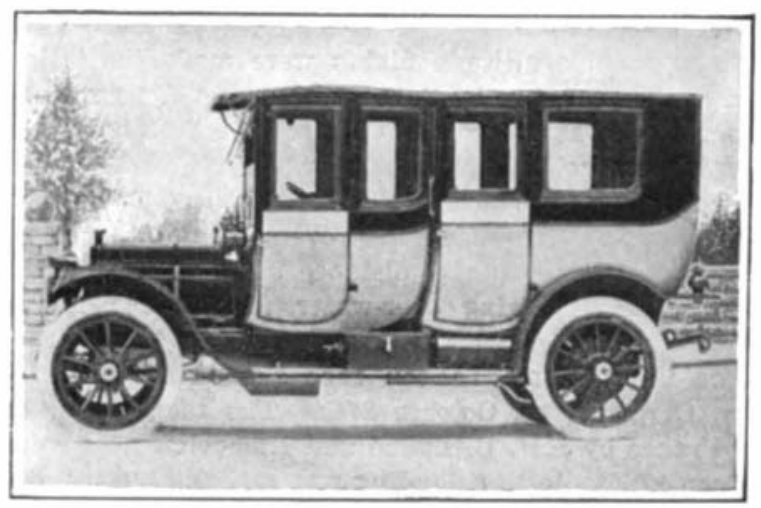

Fig. 11.-An American 1911 model which will not survive because of its peculiar broken appearance.

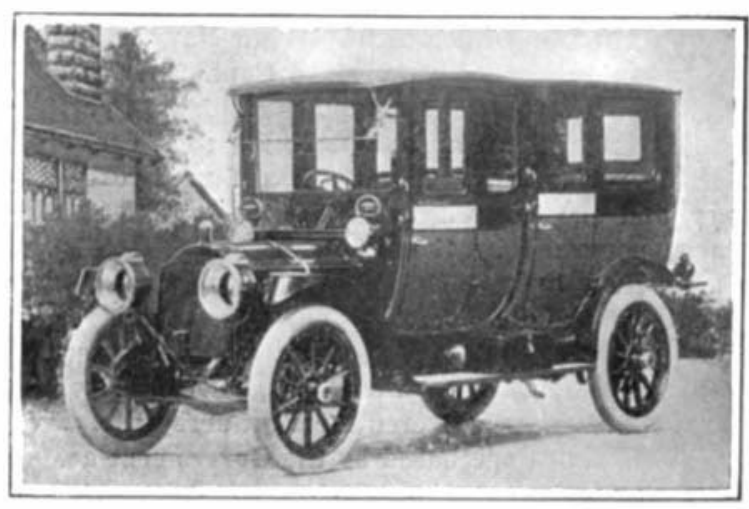

Fig. 12.-This type of 1912 is objectionable for the reason indicated in connection with Fig. 11.

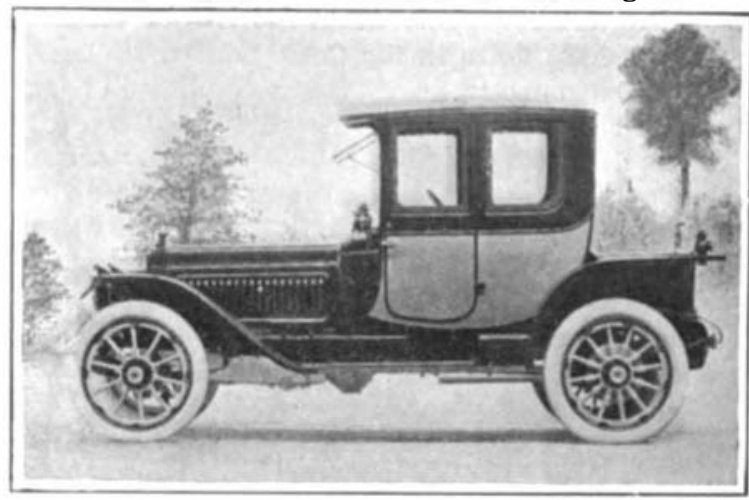

Fig. 13.-A coupe type of 1913, which looks odd because the hood and dash-cowl combined are longer than the car body.

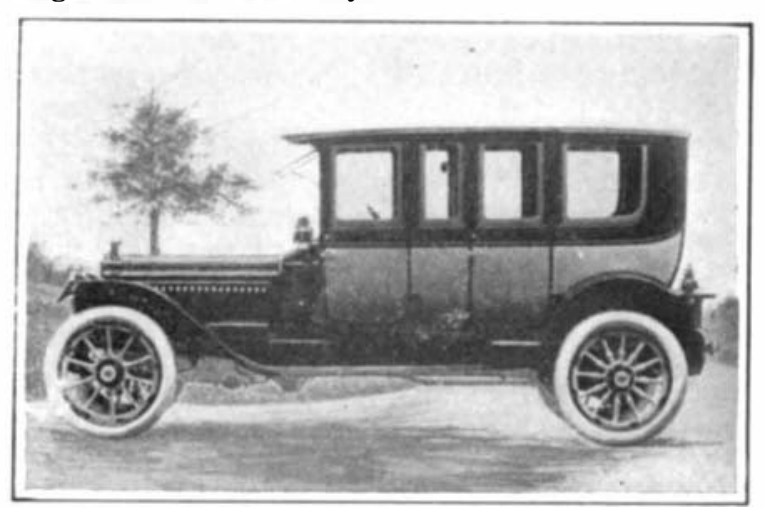

Fig. 14.-A so-called brougham, designed in America in which it is difficult to pick flaws. of skidding are reduced to a minimum in this design, and a number of racing cars constructed on these lines have proven that greater speed can be attained. The tendency toward "stream-line" bodies is clearly evident although opinions differ as to the ultimate design which will be evolved. To assist the reader in forming his own opinion of what the car of the future will look like, I am showing herewith types of body construction in chronological order, from 1903 to 1913

The cars shown in Figs. 1, 2, and 3 were made for the German emperor in 1903, 1905 and 1907, respectively, and therefore may be said to represent the best type of these years. The first two are "rear-entrance" cars, built in this manner chiefly for the reason that the problem of efficient mudguards and running boards had not yet been solved. They are clearly attempts at producing something comfortable and suitable for motor propulsion, and still suggestive of the carriage maker's hand in the design. The manufacturers of the chassis and motors were already striking out in new directions at that time, but the body-builders were still hampered by the traditions of the carriage industry.

Fig. 3 shows a car which resembles the machines of to-day. It could be driven down Broadway in New York city without causing sarcastic remarks among the pedestrians. But the backs of the seats are stiff and vertical, the upholstery is hard and thin and the driver has no protection from the elements and the dust.

The next illustration represents an immense step forward. It is a splendid car built in 1910 for the president of the French Republic by a firm which supplied Napoleon with his court carriages more than a plied Napoleon with his court carriages more than a century ago. It shows the fore-doors for the first time.
When professional chauffeurs did the bulk of the driving of motor cars, no one gave much attention to their comfort and convenience, but as soon as the private owner began to drive the car himself, the necessity of doors for the front part of the car became evident. A comparison with the preceding photographs shows some of the most characteristic and pronounced tendencies of that year. The wheel-base has grown longer, the steering column is set at a more "rakish" angle, the steering wheel is larger in diameter, the running boards are free from unnecessary boxes and litter of all kinds, and the whole car has more sweeping and pleasing lines.

Particularly graceful are the lines of the huge limousine shown in Fig. 6 . Were it not for the presence of the tool box in the very middle of the running board, it might be considered a more beautiful car than the graceful model represented by Fig. 7 . The cars were built in 1912 and 1913, respectively - that is to say, they are the leading models of these years. The sweeping curve at the rear of the top in the 1912 model is undoubtedly more pleasing than the sharp edge of the following year's type, but the neat outlines of the mudguards and hood, the lower steering column and, especially, the clear running boards are advantages which the earlier model does not show.

The American automobile industry during those years kept fully abreast of its European rival. The same faults and drawbacks are noticeable in both, but there are also in evidence all the little improvements that were added abroad, in addition to some that were invented on this side of the Atlantic. But for the peculiar construction of the body of the 1911 model in Fig. 11, which makes it resemble two independent carriage bodies, stuck together as a sort of afterthought, there is no need of apology on this maker's part. The there is no need of apology on this maker's part. The which will not survive just on account of this peculiar which will not survive just on account of this peculiar "broken" appearance. In more exaggerated form it
is shown in Fig. 16, which is a fine illustration of how an automobile body should not be designed. This style of construction is positively ugly-despite the fact that it may be comfortable and mechanically advantageous. The car also appears bigger than it really is, which may or may not be desirable, according to the opinion of the purchaser. The coupe type shown in Fig. 13 looks so odd chiefly on account of the extreme length of the hood, covering the six-cylinder motor; the hood and dash-cowl combined being longer than the entire body of the car.

It is difficult to pick fiaws in the construction of the body shown in Fig. 14-a so-called brougham. The first view of this car impresses one with the immense power and speed possibilities lying within it, and subsequent closer examination only strengthens this first impression. It is a body design which is in no way inferior to anything produced in Europe, and shows the present high state of the industry in this country The wheel-base of this car is practically thirteen feet. An extraordinary European body construction is shown in Fig. 15. This type represents the latest idea in inclosing everything within the outer lines of the body, presenting a perfectly smooth exterior and greatly reduced wind resistance. Not only are the running boards absent, but the

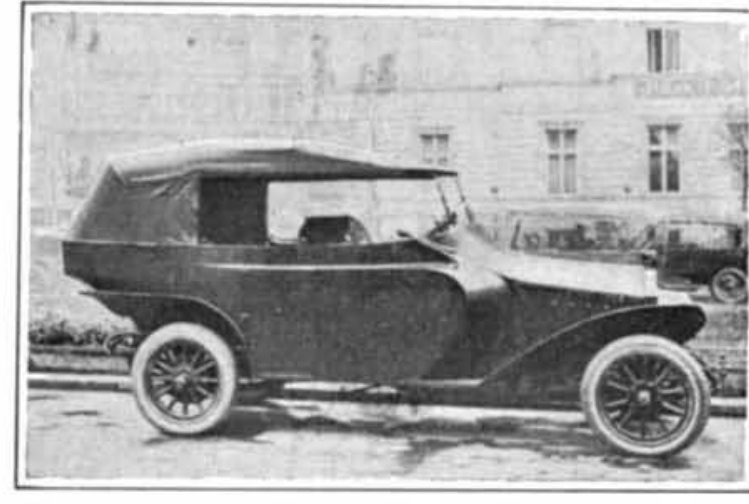

Fig. 15.-The latest European idea in inclosing everything within the outer lines. Complete protection is afforded to baggage, spare tires and tools.

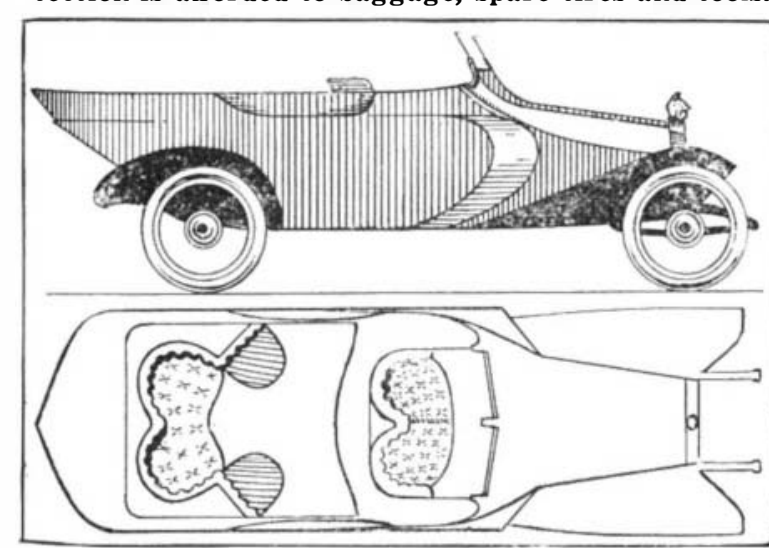

Fig. 15a.-Elevation and plan of car in Fig. 15.

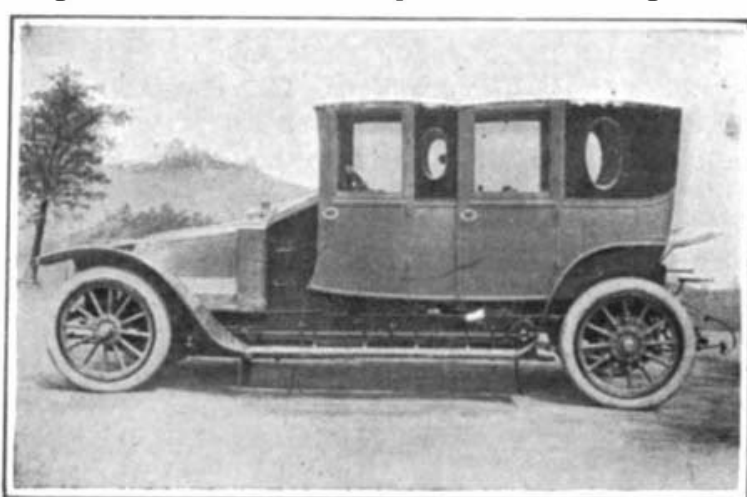

Fig. 16.-A French type of 1912, conspicuously ugly

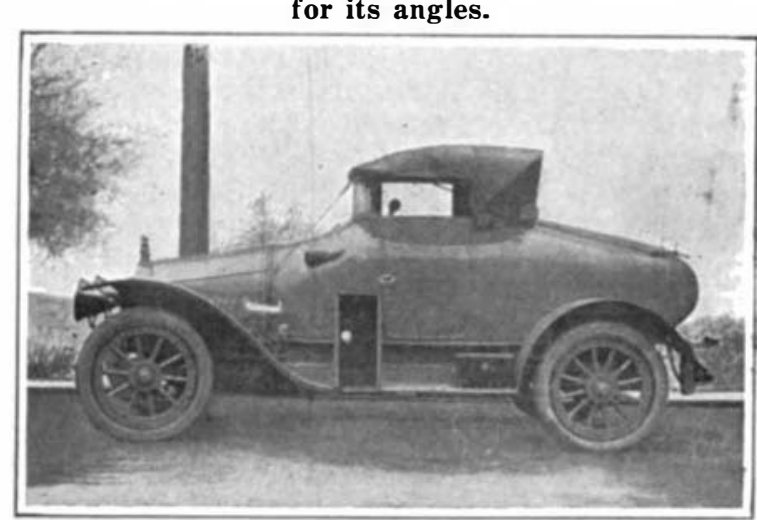

Fig. 17.-A modern French roadster in which an attempt is made to obtain smooth lines.

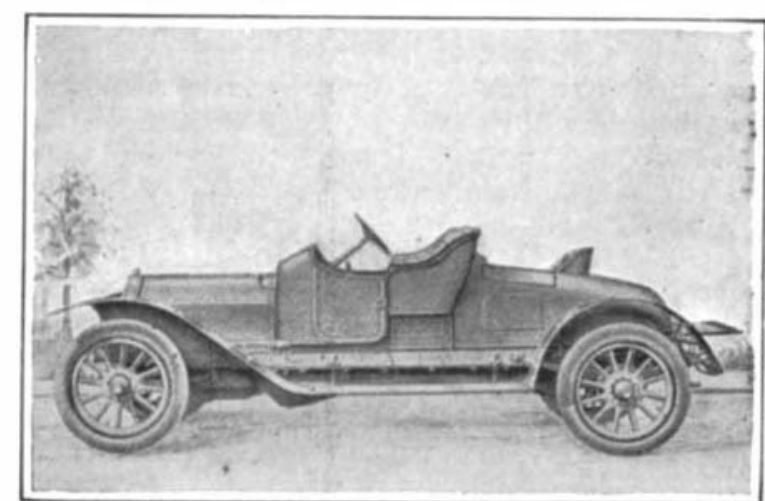

Fig. 18.-A good example of present French tendencies.

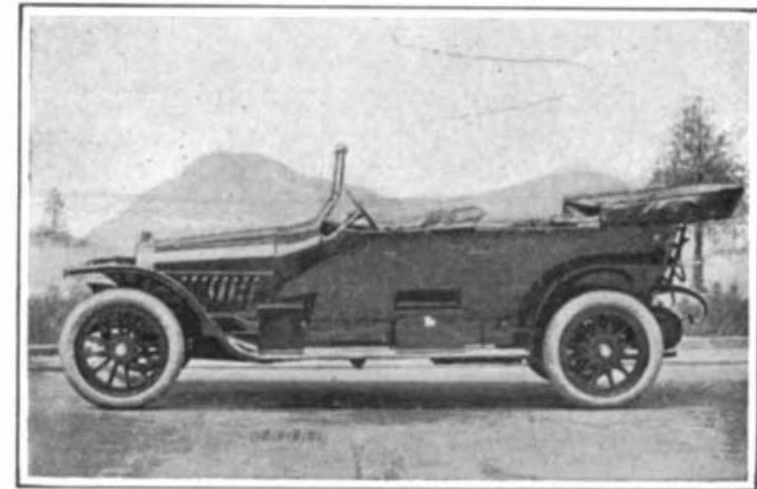

Fig. 19.-A 1912 phaeton which has a distinctive body suggesting speed and comfort. 
body itself hangs over the wheels, giving plenty of room to hangs over the wheels, giving plenty of room to the six passengers. The car is by all odds
the most radical innovation in the line of body design, and from reports from abroad is expected to be placed in commission during the coming season by at least one prominent foreign maker. The car was shown built on an ordinary chassis at the last automobile show in Berlin, Germany, and created a veritable storm of discussion and criticism. It is the most comfortable design that has as yet been evolved, and the complete protection it affords to the baggage, spare tires, tool protection it affords to the baggage, spare tires, too
boxes, etc., is of great value to the long distance tourist.

French roadsters of peculiar shape are shown in Figs. 17 and 18, but a detailed description of their features is hardly necessary, as an examination of the illustrations will disclose their peculiarities.

The designing of bodies for motor cars is becoming more and more standardized. Only a few years ago body builders made a few special designs for each manufacturer, and there were hardly any two of them alike. Then, too, the customer, particularly abroad, alike. Then, too, the customer, particularly abroad,
used to purchase his own bodies, made according to his preferences and ideas. The best example of this is the made-to-order car which some time ago was built for a wealthy American lady, and which actually was measured so as to fit her figure as closely as possible. While other automobile purchasers were not quite so particular as to just how the body fitted them, they did express preferences which the body builder had to consider. As a result, a number of freak bodies are now roaming this country as well as Europe. In many now roaming this country as well as Europe. In many
instances their owners are heartily weary of looking at them

A standardization in body design, therefore, is very desirable not only from an economical standpoint as also from the more altruistic one of beauty-as opposed to freakish contraptions. It is cheaper to build one thousand good automobile bodies after one and the same design than it is to build one thousand mediocre ones after the individual designs of one thousand persons. Besides, the metal body is driving out the wooden body, and it will not be long before the aluminium automobile body will reign supreme. In this country the use of metal bodies is increasing tre mendously, and the greater ease of manufacture, cheapness and practical indestructibility make them favorites with manufacturers demanding large quantities ites with
of bodies.

Many of the automobile manufacturers make their own bodies, in this country at least, and there is naturally an increasing tendency on their part to specialize on a few popular designs instead of pleasing each customer individually. In Europe it is still the custom in most cases to sell the chassis alone, and have the customer order his own body attached. A much greater diversity among European cars is the result, and while this may appeal to some people it is decidedly uneconomical. At any rate, one must admit that edly uneconomical. At any rate, one must admit that
a manufacturer who makes it his business to design automobile bodies knows better what would suit a customer than the latter himself.

The trend of the trade, if examined carefully, shows the preponderance of four types of cars, and by gradual elimination of the various freaks and semi-freaks produced annually these four types will be generally accepted as standard for all cars and by all manufacturers. They are: The inclosed coupé for two and four people; the limousine for five to seven people; the race-about or roadster for two people, and, finally, the open torpedo touring car for five to seven people. Thes four types cover the whole field, and until the actual cient to meet all requirements.

\section{Aeronautics and Aviation in 1912}

THE year 1912 has witnessed greater development in I aerostation and aviation than any other year since
the heavier-than-air machine was introduced. Both sciences have been put to active military use by most of the large nations, and several nations have used dirigible and aeroplanes to good effect in real warfare. At the end of 1913 it is possible that we shall have to record battles in the air, just as last year there were several collisions, not all of which were fatal. At
present guns for aeroplanes to use in attacking other present guns for aeroplanes to use in attacking other
aircraft are an established fact, one of the best of these being the invention of Lieut. Cleland Davis, U. S. A.; while Lieut. Riley W. Scott has perfected a bombdropping apparatus that leaves nothing to be desired and has won with it the Michelin prize of $\$ 15,000$. He stands ready to deliver his device to any War Department that wants it, and to instruct military aviators in its use. Lieut. Scott made a total of $S$ out of 15 hits in dropping his projectiles from a height of 2,689 feet upon a 32.S-foot target.

The principal lines of aeroplane development last year were two-military and hydro-aeroplanes. England held a contest for militury aeroplanes last fall lilie that held in France in 1911, while all the leading nations used ineroplines in the annual maneuvers. At the close of the French maneuvers no less than 72 aeroplanes were reviewed by the Minister of War, and French pilots thought nothing of flying 350 miles a day during the war game. Flights totaling 43,000 miles were made in about a week's time. In the maneuvers in Connecticut and on the Pacific coast, Wright and Curtiss army biplanes were used. It was found possible to report to headquarters by wireless from a distance of 20 miles just what was occurring at the front. The chief difficulty experienced was the inability of the machines to carry two men-the first requisite of a military aeroplane.

After meeting with pronounced success the first of last year in the continuation of his hydro-aeroplane experiments at San Diego, Cal., Glenn Curtiss sent Hugh Robinson to the Monaco meet-the first hydroaeroplane meet-in March. Robinson astonished the foreigners by his ability to navigate upon the open sea at Monaco. He had to compete only with a few other biplanes upon which floats had been hastily .fitted. The biplanes upon which floats had been hastily .fitted. The
result was that all Europe caught the "water plane" craze, and in the fall a number of hydro meets were held. At the Aero Club Show in the Grand Central Palace last May, Grover Cleveland Loening, the author of "Monoplanes and Biplanes," exhibited the first "flying boat," consisting of a monoplane, the body of which was watertight and formed a hull. He later made successful fiights with this new craft. Donnet-Lévêque, in France, applied such a tuli to a biplane in which André Beaumont flew from Paris to Bouiugne over water.

Curtiss brought out a similar flying boat and our Navy has recently purchased one. The advautage of this type of hydro-aeroplane is that it can skim the surface of the water at 50 miles per hour and make out the least danger to the occupants. As many as four persons have made a trip of an hour or more in a persons have made a trip of an hour or more in a hydro-aeroplane accident, and that was due to foolhardiness, as mentioned in a recent issue. One of these machines gives the double pleasure of flying and motor boating with the dangers of the former entirely eliminated. Wheels may be fitted for land use as well, if desired.

Aerostation in America received a severe set-back early in July, through the bursting of what was practically her only dirigible. The "Akron" exploded early in the morning of July 2nd, while maneuvering above the shallow water of the lnlet at Atlantic City. Melvin and Calvin Vanniman and the three other men that formed the "Akron's" gallant crew, fell to their deaths. Melvin Vanniman, since his attempt at crossing the Atlantic with Wellman in the "America," had given his entire energy to the accomplishment of this feat. Finally, securing the financial backing required, he had constructed the "Akron" for this purpose; but while building her he made: an improvement which consisted of weaving wire in the clotli forming the gals bag, so that the completed envelope was wirewound like the barrel of a wirewound gun. The gas bag would thus be strong enough to withstand the increase in pressure arising from heating and consequent expansion of gas. The envelope of the "Akron" Vanniman thought was strong enough to withstand a considerably increased pressure, and it is believed he allowed the pressure to increase when the sun came from behind a cloud, with the result that a weak section of the envelope gave way.

An equally appalling aviation accident that occurred on July 1st was the flinging out of her 70 horse-power Blériot monoplane of Miss Harriet Quimby and W.
A. P. Willard, at the Boston meet. Willard, who was some distance behind Miss Quimby, was flipped from his seat probably as the result of suddenly developed his seat probably as the result of suddenly developed gyroscopic force, and Miss Quimby immediately fol-
lowed him. Both fell a thousand feet into shallow lowed him. Both fell a thousand feet into shallow
water and were killed. Miss Quimby, shortly before, had won the honor of being the first and only aviatress to this day to fly across the English Channel. She used a 50 horse-power Blériot and made the flight from Dover to Calais in foggy weather. She landed at Hardelot 40 minutes after starting. Her accident at Boston would not have resulted fatally had two deBoston would not have resulted fatally had two de-
vices, which have since been perfected, been obtainable vices, which have since been perfected, been obtainable
at that time. One of these is a gyroscope-compressed air automatic control for aeroplanes, which has been arranged to give automatic stability in all directions, and the other is a safety parachute of Japanese silk weighing $61 / 2$ pounds, which is carried on an aviator's back like a knapsack and opens instantly when he is thrown out of his machine. Both are the inventions of Americans

While there have been many long-distance aeroplane fights abroad, such as the 650-mile flight of Andemilr in two days from Paris to Berlin, the only one of not in America was the 1,ro()-mile trip of Nuthony Jimnus
from Omaha, Neb., to New Orleans in a Benoist hydroaeroplane. Jannus' flying time was 31 hours $4: 3$ mit utes. He stopped at many towns en route, and gave exhibition flïghts. The $4 \pi 1$ miles from Kansas City to St. Louis were covered by Jannus alone in 9 hours 23 minutes, which is one fourth faster time than the express trains make. The 1,000 miles remaining were covered with a passenger and an 85-pound case of beer. The journey was made without any serious accident, the winding rivers being followed the entire distance. The replacements to plane and engine did not amount to $\$ 20$

All speed records were broken in the Bennett Cup race at Chicago on September 9th, when Vedrines, on a 140 horse-power Deperdussin "monocoque," covered the 124.8-mile course in 1 hour 10 minutes 57 seconds at the rate of $1051 / 2$ miles per hour. He covered 10 kilometers in 3 minutes $273 / 5$ seconds, or at a rate of 107.68 miles per hour. The American monoplane with 160 horse-power Gnome motor, built to defend the cup, was never flown.

As for the duration record, this was again raised by Fourny on a Maurice Farman biplane from 11 hours to 13 hours and 18 minutes on September 11th. A distance of 628 miles was covered over a 10-mile circular course. In America Lieut. John H. Towers, on October 6th, made an endurance record of 6 hours and $10 \mathrm{~min}-$ utes with a 75 horse-power Curtiss hydro-aeroplane, while on October 31st Walter E. Johnson, at Bath, N. Y., carried a passenger for 3 hours $51 \frac{11 / 2}{2}$ minutes with his Thomas biplane fitted with a 65 horse-power Kirkham 6-cylinder motor. The greatest total distance covered across country in a single day was the 570 miles between Valenciennes and Biarritz, traversed by
Pierre Daucourt in his 50 horse-power Borel monoplane Pierre Daucourt in
also on October 6th.

Three notable altitude flights were made the latter part of the year, two by Garros and one by Legagneaux. The record was raised each time 1,000 feet or more. Garros now holds it with 5,801 meters (19,032 feet), subject to revision. He made the record at Tunis and then flew to Sicily-160 miles oversea-and thence to Italy and Rome-a total distance of 700 miles. This was the most daring over-water flight since Lieut. Bague was lost.

- The international balloon race started from Stuttgart, Germany, on October 27th. The race was won balloon "Picardie." A landing was made near Moscow, and a new record of 1,364 miles was set up. Leblanc was second with 1,240 miles, and John Watts of St. Louis, third, with 1,000 miles.

The acquirement of aeroplanes by our Navy will probably be rapid from now on, since Capt. Charles deF. Chandler has invented a catapult, making it possible to successfully launch an aeroplane from the deck of a battleship. The Navy already has four hydro-aeroplanes, and one flying boat in addition to eight or ten biplanes possessed by the Army. Recent experiments biplanes possessed by the Army. Recent experiments be easily located when completely submerged even in rather muddy water. The wreck of the American warship "Philadelphia," which stranded off Tripoli in 1803, was recently discovered from an aeroplane.

Future biplanes purchased by the Government are all to have monoplane bodies of streamline form, bodies similar in many respects to that of the Benoist biplane used by Jannus. The twin-motored and duplicate twinpropellered Wright biplane which the late Howard W. Gill was to have flown in the Gould-Scientific AMERICAN $\$ 15,000$ two-motor prize contest on July 4th last, also had a body with aviator's seat therein. The above event was declared off as Mr. Gill was the only entrant ready to appear at the stated time and place. In England lately successful flights have been made with a two-motored biplane, and Grahame-White expects to fly to America in 30 hours next summer with a machine fitted with four motors of 250 horse-power each. The idea promulgated by Mr. Edwin Gould has, therefore, fructified.

\section{Subsidizing the Motor Car}

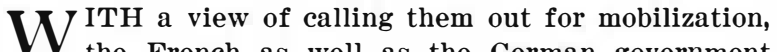
allows annual subsidies to owners of power provided these are of the approved types according to the War Department specifications. The leading constructors are now building their wagon trucks with this end in view, and this leads to a standardizing of the chassis as regards certain general sizes and other features, not interfering, however, with individual construction. The rules call for a t-cylinder motor in all cases. and the preferred type carries about 3 tons load. Strict rules provide that the French cars shall be built entirely of home material. The 3 -ton car receives a first subsidy known as purchase subsidy of $\$ 600$ and an upkeep subsidy of $\$ 200$ during 3 years following. In Germany the 5-ton wagon has subsidies of $\$ 1,000$ and $\$ 250$, resilectively, for the same cases. Great Britain is now entering the movement, but the subsidies, $\$ 40$ to $\$ 60$, ind $\$ 75$ inmuil, alle much smiller. Austriil has a similill sirstem. 